ISSN 1980-5098

\title{
INFLUÊNCIA DA LUMINOSIDADE E FERTILIZANTES NOS TEORES DE METILXANTINAS E COMPOSTOS FENÓLICOS EM FOLHAS DE ERVA-MATE
}

\author{
INFLUENCE OF LIGHT AND FERTILIZERS ON METHYLXANTHINES AND PHENOLIC \\ COMPOUNDS IN LEAVES OF MATE TEA
}

\author{
Überson Boaretto Rossa ${ }^{1}$ Alessandro Camargo Angelo ${ }^{2}$ Jorge Zbigniew Mazuchowski ${ }^{3}$ Danielle \\ Janaina Westphalen ${ }^{4}$ Catia Nara Tobaldini Frizon ${ }^{5}$ Carlos Eduardo Nogueira Martins ${ }^{6}$
}

\begin{abstract}
RESUMO
A erva-mate (Ilex paraguariensis A. St.-Hil.) é uma espécie climácica, bastante adaptada ao sombreamento, por isso, cada vez mais cultivada em consórcio com outras espécies madeiráveis, e de forma mais intensiva de que a sua exploração tradicional. Para manter níveis de produtividade adequados é necessário o uso de fertilizantes que deem aporte nutricional às plantas. Os teores de substâncias do metabolismo secundário da planta, como as metilxantinas e os compostos fenólicos, podem ser afetados por esse tipo de manejo mais intensivo, já que o sombreamento e a adubação influenciam a fisiologia da planta. Objetivando a determinação de teores de metilxantinas e compostos fenólicos totais em folhas de erva-mate, produzidas sob luminosidade aparente de 30, 45 e 60\%, e fertilização convencional (FC) $\left(\mathrm{N}, \mathrm{P}_{2} \mathrm{O}_{5}\right.$ e $\mathrm{K}_{2} \mathrm{O}$ 15-05-30) e de liberação lenta ( $\mathrm{N}, \mathrm{P}_{2} \mathrm{O}_{5}$ e $\mathrm{K}_{2} \mathrm{O}$ 15-08-12), foi proposto esse estudo para duas estações de crescimento nos anos de 2011 e 2012. A fertilização da erva-mate associada aos níveis de luminosidade aparente não promoveram o aumento de teores de metilxantinas totais e compostos fenólicos totais. A luminosidade aparente de $30 \%$ estabeleceu o melhor indicador para obtenção de metilxantinas, sendo que a fertilização FC apresentou a maior produção de metilxantinas, quando submetida à luminosidade aparente de $30 \mathrm{e} 45 \%$. Houve incremento do teor dos compostos fenólicos da estação de crescimento 2011 para 2012 promovido pelos tratamentos fertilizados com FLL e FC sob a luminosidade aparente de $30 \%$ e $60 \%$.

Palavras-chave: Ilex paraguariensis; fenóis totais; alcaloides; adubação mineral.
\end{abstract}

\section{ABSTRACT}

The Mate Tea (Ilex paraguariensis A. St.-Hil.) is a climax species adapted to low light, and that is why is more cultivated in consortium with other species of woods and more intensively that their traditional exploration. To maintain adequate levels of productivity, it is necessary the use of a fertilizer that gives nutritional intake to plants. The levels of substances of plant secondary metabolism as methylxanthines and phenolic compounds may be affected by this type of intensive management since the shading and fertilization influence the physiology of the plant. Aiming the determination of the levels of totals methylxanthines and

1 Licenciado em Ciências Agrárias, Dr., Professor do Instituto Federal Catarinense, Campus Araquari, Rodovia BR 280, Km 21, Caixa Postal 21, CEP 89245-000, Araquari (SC), Brasil. boarettorossa@gmail.com

2 Engenheiro Florestal, Dr., Professor do programa de Pós-graduação em Engenharia Florestal, Universidade Federal do Paraná, Campus III, Av. Pref. Lothário Meissner, 900, CEP 80210-170, Curitiba (PR), Brasil. alessandrocangelo@gmail.com

3 Engenheiro Agrônomo, Dr., Pesquisador e Extensionista do Instituto EMATER, Rua da Bandeira, 500, CEP 80035-270, Curitiba (PR), Brasil. jorgemazuchowski@emater.pr.gov.br

4 Engenheira Agrônoma, Doutoranda do programa de Pós-graduação em Engenharia Florestal, Universidade Federal do Paraná, campus III, Av. Pref. Lothário Meissner, 900, CEP 80210-170, Curitiba (PR), Brasil. daniellejanaina76@gmail.com

5 Química Industrial de Alimentos, Doutoranda em Engenharia de Alimentos, Universidade Federal do Paraná, Centro Politécnico, Bloco da Engenharia Química, Rua Francisco H. dos Santos, s/n, Caixa Postal 19011, CEP 81531-980, Curitiba (PR), Brasil. cfrizon@yahoo.com.br

6 Zootecnista, PhD., Professor do Instituto Federal Catarinense, Campus Araquari, Rodovia BR 280, Km 21, Caixa Postal 21, CEP 89245-000, Araquari (SC), Brasil. carlos.martins@ifc-araquari.edu.br

Recebido para publicação em 9/05/2013 e aceito em 13/05/2016 
phenolic compounds, produced under relative brightness of 30, 45 and $60 \%$, and conventional fertilization $\left(\mathrm{N}, \mathrm{P}_{2} \mathrm{O}_{5}\right.$ and $\mathrm{K}_{2} \mathrm{O}$ 15-05-30) and slow release $\left(\mathrm{N}, \mathrm{P}_{2} \mathrm{O}_{5}\right.$ and $\mathrm{K}_{2} \mathrm{O}$ 15-08-12), this study was proposed for two growing seasons $2011 \mathrm{e} 2012$. The fertilization of mate tea associated with the apparent brightness levels did not promote increased levels of totals methylxanthines and phenolic compounds. The apparent brightness of $30 \%$ established the best indicator to obtain methylxanthines, and the conventional fertilization had the highest fertilization production of methylxanthine, when subjected to the apparent brightness of 30 and $45 \%$. There was an increase of the content of phenolic compounds of the growing season 2011 to 2012 promoted by the fertilization treatment with FLL and FC under the apparent brightness of $30 \%$ and $60 \%$. Keywords: Ilex paraguariensis; total phenols; alkaloids; mineral fertilizer.

\section{INTRODUÇÃO}

A erva-mate (Ilex paraguariensis A. St.-Hil.) é componente dos sistemas tradicionais silviculturais mais antigos da região sul do Brasil. Por ser espécie climácica, cresce espontaneamente em ambiente sombreado do sub-bosque das matas de pinheiro-brasileiro (Araucaria angustifolia (Bertol.) Kuntze 1898) (OLIVEIRA; ROTTA, 1985) e matas subtropicais existentes na região, adaptando-se facilmente em consórcios com outras espécies florestais madeiráveis. Esses sistemas caracterizam-se pela oferta diversificada de produtos e serviços que apostam na estabilidade econômica e social do produtor rural (MAZUCHOWSKI, 2004), entre eles, a produção de folhas de erva-mate com compostos conhecidos como biofuncionais (FILIP, 2001) que podem elevar o valor do produto pago ao produtor.

Os sistemas consorciados constituem uma promissora atividade florestal, capaz de contribuir para o desenvolvimento sustentável, mediante o uso de produtos de base florestal sem pressionar áreas remanescentes de floresta nativa, satisfazendo dessa forma as demandas por energia e matéria-prima madeirável. O setor ervateiro tem necessidade de conversão dos ervais de pleno sol para ervais sombreados (MACCARI JUNIOR; MAZUCHOWSKI, 2000). Este procedimento é realizado visando elevar a agregação de valor à produção, uma vez que o produtor recebe maior valor pela erva-mate sombreada, em função de suas características organolépticas atribuídas ao produto industrializado (NIETSCHE, 2002).

Pela evolução da tecnologia e engenharia química de alimentos, a cada dia diferentes produtos são obtidos das folhas de erva-mate, somando-se a isso observa-se o interesse dos consumidores por produtos de origem natural, reforçando o consumo de bebidas como: chimarrão, tereré, chá-mate queimado e chá-mate verde, mate solúvel e chá pronto para beber, bebidas energéticas e sucos (MAZUCHOWSKI; RUCKER, 1993). Pelas características de plasticidade da cultura da erva-mate, devido a sua grande diversidade de compostos químicos foliares, a espécie também é empregada na produção de medicamentos, produtos de higiene geral e de uso pessoal, insumo para outros alimentos, sendo excelente bactericida, esterilizante e antioxidante, podendo ser usada no tratamento de esgotos e reciclagem do lixo urbano (MACCARI JUNIOR; MAZUCHOWSKI, 2000).

O desenvolvimento de novos produtos da erva-mate valoriza os integrantes da cadeia produtiva, especialmente pela ampliação dos mercados interno e internacional, bem como pela oferta de uma gama de produtos alternativos, decorrentes do desenvolvimento de opções de utilização (BUGARDT, 2000). A variação natural das condições ambientais e dos tipos de manejo dos ervais determina a diferenciação da matéria-prima para as variadas destinações industriais da espécie (MERCOMATE, 1993).

O consumo pelos povos tradicionais, bem como pesquisas científicas comprovam a influência das propriedades da folha de erva-mate no organismo humano, atuando nos sistemas nervoso central, cardiovascular, renal e digestivo, como diurético, antioxidante, eupéptico e colerético, entre outras (GUGLIUCCI, 1996; SCHINELLA et al., 2000). Além dos efeitos terapêuticos, estudos sobre a espécie têm revelado diversas propriedades nutritivas e fisiológicas, conferindo um grande potencial de aproveitamento (VALDUGA, 1995). Entre os componentes responsáveis pelas propriedades da erva-mate destacam-se as metilxantinas totais (cafeína, teofilina e teobromina), bem como compostos fenólicos totais.

Fisiologicamente para as plantas, as metilxantinas (MTX) e os compostos fenólicos (CFT) são metabólitos secundários com funções ecológicas importantes, como proteção contra 
herbívoros e patógenos, ação alelopática, além de agir como atrativos para animais polinizadores (TAIZ; ZEIGER, 2004). Esses metabólitos secundários são derivados do nucleotídeo purina, sendo também conhecidos como alcaloides purínicos. A metilxantina mais abundante na natureza é a cafeína $(1,3,7$ trimetilxantina), seguidapelateobromina(3,7dimetilxantina).Ateofilina(1,3 dimetilxantina)eoutroscompostos se encontram em pequenas quantidades, podendo ser intermediários da biossíntese e/ou catabolismo da cafeína (ASHIHARA; SUZUKI, 2004).

Os compostos fenólicos pertencem a uma classe de substâncias químicas que incluem uma grande diversidade de estruturas, simples e complexas, derivadas da fenilalanina e da tirosina, que possuem em sua estrutura pelo menos um anel aromático com um ou mais grupamentos hidroxilas (NACZK; SHAHIDI, 2004). Esta classe de compostos pode ser dividida em flavonoides (antocianinas, flavonóis e isoflavonas, entre outros) e não flavonoides (ácidos fenólicos e derivados) (ANGELO; JORGE, 2007). Os compostos fenólicos bioativos de origem vegetal apresentam atividade antioxidante, podem atuar como agentes redutores, sequestrantes de radicais livres, além de agirem como quelantes de metais (MELLO; GUERRA, 2002). Eles apresentam uma gama de efeitos biológicos, incluindo as ações antioxidante, antimicrobiana, anti-inflamatória e vasodilatadora (DEGÁSPARI; WASZCZYNSKY, 2004), sendo atribuídos a essa classe de constituintes os benefícios do consumo da infusão de erva-mate (OLIVEIRA et al., 2006; BRAVO; GOYA; LECUMBERRI, 2007).

A composição química da erva-mate pode variar com o tipo de cultivo, clima, condições agronômicas, idade da planta e variabilidade genética (MAZZAFERA, 1994; DA CROCE, 2002; SCHERER et al., 2002). Diferentes formas de condução da cultura a campo podem modificar sua composição qualitativa e quantitativa e, consequentemente, a atividade dos constituintes bioativos como metilxantinas e compostos fenólicos. Gobbo-Netto e Lopes (2007) destacam os nutrientes e a luminosidade como fatores importantes de influência no conteúdo de metabólitos secundários das plantas.

Resultados preliminares dos trabalhos de pesquisa concluíram que a diferença dos teores das substâncias químicas vinculadas ao sabor é devida, principalmente, ao fator luminosidade (RACHWAL et al., 1998). Conhecer a composição de bioativos da erva-mate é um fator importante para aumentar o apelo ao consumo do produto, entretanto, trabalhos mostram que existem variações nos teores de um mesmo componente em amostras estudadas (BORTOLUZZI et al., 2006; CARDOSO JÚNIOR, 2006). Dessa forma, é necessário estudar os fatores que podem causar alterações nesses compostos químicos, como diferentes níveis de luminosidade aparente e fertilizações em sistemas de produção a campo. Devido ao fato de a erva-mate ser rica em metilxantinas e compostos fenólicos, este trabalho tem como objetivo a quantificação desses bioativos presentes nas folhas de indivíduos submetidos a níveis distintos de luminosidade e efeito de diferentes tecnologias de fertilização.

\section{MATERIAL E MÉTODOS}

A área de realização da pesquisa encontra-se a 1110 m s.n.m. e situa-se sob as coordenadas geográficas $25^{\circ} 20^{\prime} 18,52$ 'S e $51^{\circ} 10^{\prime} 54,67^{\prime}$ 'O. De acordo com Instituto Agronômico do Estado do Paraná (1994), as características climáticas da região enquadram-se na classificação que define o tipo Cfb (temperado) estabelecido por Köppen. A unidade fitoecológica é definida por Roderjan et al. (2002) como Floresta Ombrófila Mista, sendo que o tipo de solo da área de pesquisa é classificado como Cambissolo Háplico álico latossólico textura muito argilosa a proeminente, relevo suave ondulado (EMBRAPA, 2006). O experimento foi conduzido entre os meses de dezembro de 2010 a dezembro de 2012, em erval comercial de 25 anos de idade, em sistema de consórcio com eucalipto de seis anos de idade, à época de implantação. $\mathrm{O}$ erval foi formado com mudas produzidas a partir de sementes coletadas em árvores-matrizes nativas da própria fazenda, sendo plantadas em 1986, no espaçamento $4 \times 2 \mathrm{~m}$. A introdução dos eucaliptos foi realizada no espaçamento de $8 \times 10 \mathrm{~m}$ e, atualmente, o povoamento encontra-se com seis anos de idade, apresentando altura média de $13 \mathrm{~m}$.

Os tratamentos foram caracterizados por diferentes combinações do fator luminosidade aparente (30, 45 e 60\%), com a técnica de fertilização (SF: sem fertilizante; FC: aplicação de fertilizante convencional e FLL: aplicação de fertilizante de liberação lenta). Para o estabelecimento dos gradientes de luminosidade 
de 30, 45 e $60 \%$, foi realizado o abate de árvores de eucalipto até atingir o gradiente proposto, medido através de luxímetro digital portátil (modelo ICEL LD-550), possibilitando maior ou menor entrada de luz sob as erveiras nos tratamentos. Durante o período de condução do experimento, em uma regularidade de três meses, coincidindo com a mudança de cada estação (verão, outono, inverno e primavera) foram realizadas aferições com o luxímetro para assegurar os três níveis de luminosidade. Para a tomada de dados de luminosidade, foi posicionado sensor fotométrico do luxímetro no hemisfério norte da copa de cada planta útil da parcela, nos horários das 8,12 e 15 horas, durante três dias seguidos.

Para a fertilização das plantas, foram utilizados produtos químicos de duas tecnologias distintas: o fertilizante convencional de pronta solubilidade e o fertilizante de liberação lenta com solubilidade controlada. O primeiro, com formulação comercial contendo $15 \%$ de $\mathrm{N}, 5 \% \mathrm{P}_{2} \mathrm{O}_{5}$ e $30 \%$ de $\mathrm{K}_{2} \mathrm{O}(15-05$ 30 ), em uma dosagem de $200 \mathrm{~g} \mathrm{ano}^{-1}$ por árvore, que foi aplicada em duas doses iguais de $100 \mathrm{~g}^{2} \mathrm{no}^{-1}$ por árvore, nos meses de setembro e dezembro. Para aplicação desse fertilizante foi realizada abertura de cova circular de aproximadamente $20 \mathrm{~cm}$ de profundidade com auxílio de enxada, em torno do caule de cada árvore na projeção da copa. O fertilizante de liberação lenta, com formulação de $15 \%$ de $\mathrm{N}, 8 \% \mathrm{P}_{2} \mathrm{O}_{5}$ e $12 \%$ de $\mathrm{K}_{2} \mathrm{O}$ (15-08-12), foi aplicado em setembro, em uma única vez e em dosagem de $30 \mathrm{~g}^{2} \mathrm{ano}^{-1}$ por árvore. Para fornecimento individual a cada árvore, foram abertas três covas simples de $20 \mathrm{~cm}$ de profundidade, distribuídas ao redor do caule na projeção da copa.

Para compor as amostras foi realizada coleta de folhas das erveiras, coincidindo com a estação de poda, que ocorreu nos meses de julho de 2011 e 2012, quando foram colhidas 100 folhas frescas de erva-mate de cada planta, que foram coletadas do terço superior, médio e inferior da copa, conforme Oliveira (2001). O material vegetal foi lavado triplamente com água corrente deionizada, e foi submetido à secagem em forno micro-ondas (potência útil de $1100 \mathrm{~W}$, frequência de $2450 \mathrm{MHz}$, velocidade do prato giratório de $3 \mathrm{rpm}$ ), em 2 ciclos de 2 minutos e 1 ciclo de 1 minuto, até atingir peso constante. Após a secagem das folhas, realizou-se a moagem das amostras em moinho com câmara de aço inoxidável tipo Willey, equipado com peneira de $0,5 \mathrm{~mm}$, visando à obtenção de material fino e homogêneo, para em seguida realizar a análise química e determinação dos teores de MXT e CFT.

\section{Quantificação de metilxantinas totais}

As metilxantinas foram extraídas de $2 \mathrm{~g}$ de amostras de erva-mate, com $4 \mathrm{~mL}$ ácido sulfúrico em banho de água, seguido por neutralização com hidróxido de sódio a $40 \%$, conforme metodologia descrita por Dutra, Hoffmann-Ribani e Ribani (2010). Os extratos foram filtrados em membrana filtrante politetrafluoroetileno (PTFE) de 0,45 $\mu \mathrm{m}$ da Millipore e foram diretamente analisados após filtração. Alíquotas de $5 \mu \mathrm{L}$ da amostra foram injetadas em um cromatógrafo a líquido de alta eficiência (CLAE) da marca Agilent, com sistema automático de injeção (ALS), com detector de arranjo de diodos (DAD), modelo 1200, controlado pelo software EZ Chrom Elite. Foi utilizada coluna Zorbax Eclipse XDB-C18, (4.6 x $150 \mathrm{~mm}, 5 \mu \mathrm{m})$. A fase móvel utilizada foi água/metanol $(80: 20 \mathrm{vv})$, com fluxo de $1 \mathrm{~mL} / \mathrm{min}$, isocrático. A quantificação dos extratos das amostras foi realizada por padronização externa e as determinações de cada amostra conduzidas em duplicata. O limite de detecção (LD) foi definido pelo parâmetro da curva analítica, calculados como a mínima concentração 3,3 x (SD/S), sendo SD (desvio padrão) o valor de três vezes a altura do ruído e S (slope) a inclinação da curva analítica (SHABIR, 2003). O valor do limite de quantificação (LQ) foi calculado por 3 x LD. Avaliou-se a seletividade pela comparação dos tempos de retenção dos picos obtidos na separação frente aos dos padrões, e pela comparação dos espectros com o dos respectivos padrões em um banco de dados.

\section{Quantificação dos compostos fenólicos totais (CFT)}

A extração foi realizada de acordo com a metodologia descrita por Dutra et al. (2010). Inicialmente, $100 \mathrm{~mL}$ de solução água:etanol 1:1 (v/v) foram adicionados a $2 \mathrm{~g}$ de erva-mate e a mistura foi mantida por 12 horas à temperatura ambiente. Seguiram-se três extrações com $25 \mathrm{~mL}$ da solução hidroetanólica a $50 \%$ sob refluxo por 30 minutos cada, e em seguida o extrato foi filtrado. O conteúdo de CFT foi determinado 
espectrofotometricamente pelo método de Folin-Ciocalteau, de acordo com metodologia descrita por Singleton et al. (1999). Após 5 minutos, $500 \mu \mathrm{L}$ dos extratos foram misturados a 2,5 $\mathrm{mL}$ de reagente Folin-Ciocalteau (1:10) e 2,0 mL de solução de carbonato de sódio $\left(\mathrm{Na}_{2} \mathrm{CO}_{3}\right)(4 \% \mathrm{~m} / \mathrm{v})$. Após 120 minutos de reação na ausência de luz e temperatura ambiente, a absorbância foi medida em $740 \mathrm{~nm}$. Como padrão, empregou-se o ácido 5-cafeoilquínico (5CQA), adquirido da marca Sigma, sendo os resultados expressos em mg equivalentes de 5CQA/g de amostra.

\section{Análise estatística}

O delineamento experimental foi de blocos ao acaso, em esquema fatorial $3 \times 3$, com 9 tratamentos e 3 repetições, totalizando 27 parcelas de aproximadamente $180 \mathrm{~m}^{2}$, com 10 plantas úteis em cada parcela. Para a seleção das 10 plantas foi aplicada a fórmula de Stein (STEEL; TORRIE, 1960) dentre as 20 plantas passíveis de utilização existentes na parcela. Os dados foram analisados em delineamento em blocos ao acaso utilizando modelos mistos, sendo os efeitos fixos: a fonte de fertilização, o nível de luminosidade, o ano e suas interações; e os efeitos aleatórios: bloco e o erro residual. Os dados passaram pelos pressupostos de normalidade e homogeneidade de variâncias e, quando observado efeito significativo, as médias entre tratamentos foram comparadas utilizando-se o teste de Tukey, considerando nível de significância de 5\%. Para verificar o incremento ocorrido entre os dois anos de produção, foi aplicado o teste de F. As análises foram realizadas com auxílio do programa estatístico JMP”.

\section{RESULTADOS E DISCUSSÃO}

A Câmara Setorial da Cadeia Produtiva da Erva-Mate do Paraná aponta a relevância dos trabalhos de pesquisa que buscam a compreensão de aspetos técnicos silviculturais da erva-mate, em especial das práticas de sombreamento e fertilização para melhorar a produtividade (MAZUCHOWSKI, 2000). O autor também menciona os estudos sobre a composição química da espécie considerando aspectos edafológicos (altitude, tipo de solo e microclima) do sítio em que está sendo produzida, visando incrementar a valorização do produto comercial pela indústria. Na Tabela 1 encontram-se os teores foliares de MTX e CFT em ervamate produzida em diferentes luminosidades aparente e fertilizações, para os dois anos de experimentação.

\section{Metilxantinas totais}

Na estação climática de crescimento de 2011, os teores de MTX produzidas pelas erveiras não diferiram entre os tratamentos de luminosidade e fertilização, exceto aquelas submetidas a $45 \%$ de luminosidade e fertilizadas com FLL, as quais apresentaram teores inferiores aos demais tratamentos, de $0,920 \mathrm{mg} \mathrm{g}^{-1}$ (Tabela 1). Esse resultado foi semelhante ao relatado no estudo de Rachwal et al. (2002), os quais não observaram alteração da concentração de MXT na cultura da erva-mate sombreada, submetida à luminosidade aparente de até $60 \%$.

As maiores produções de MXT no ano de 2011 foram de 1,081 e 1,12 $\mathrm{mg} \mathrm{g}^{-1}$, sendo correspondente aos tratamentos com luminosidade de $45 \%$ SF e FC. Por outro lado, na estação de crescimento de 2012 , os valores quantitativos de MXT foi de $1,26 \mathrm{mg} \mathrm{g}^{-1}$, das erveiras sob luminosidade de $30 \%$ e fertilizadas com FLL. As erveiras submetidas à luminosidade de $45 \%$ e fertilizadas com FC produziram $9,10 \%$ mais MXT $\left(1,21 \mathrm{mg} \mathrm{g}^{-1}\right)$ quando comparado com o SF $\left(1,10 \mathrm{mg} \mathrm{g}^{-1}\right)$. Neste nível de luminosidade, o teor correspondente a $1,08 \mathrm{mg} \mathrm{g}^{-1}$, foi verificado nas erveiras fertilizadas com FLL.

Na luminosidade de 30\% houve um incremento nos teores de MXT para todos os tipos de fertilização, correspondentes a 24,2, 25,5 e 31,3\% para SF, FC e FLL, respectivamente (Tabela 2). Esses dados confirmam estudo de Coelho et al. (2000) no qual foi observado que em folhas mais sombreadas de erva-mate há um maior investimento em substâncias químicas de defesa, como as MXT, que podem agir contra fungos e insetos desfolhadores, agentes biológicos presentes tipicamente em ambientes com menor níveis de insolação.

Na luminosidade aparente de 45 e $60 \%$ com os tratamentos SF e FC, as folhas não apresentaram incremento de MXT entre as estações de crescimento, entretanto, percebe-se um efeito dos fertilizantes para 
TABELA1: Teores foliares de metilxantinas totais e compostos fenólicos totais nas folhas de erva-mate produzidas em diferentes níveis de luminosidade e fertilizantes, no período de dois anos.

TABLE 1: Foliar content of total methylxanthines and phenolic compounds in mate tea leaves, produced in different levels of luminosity and fertilizers in the period of two years.

\begin{tabular}{lcccccc}
\hline \multirow{2}{*}{ Tratamentos } & \multicolumn{5}{c}{ Luminosidade média ambiental } \\
\cline { 2 - 7 } & $60 \%$ & $45 \%$ & $30 \%$ & $60 \%$ & $45 \%$ & $30 \%$ \\
\cline { 2 - 7 } & 2011 & \multicolumn{7}{c}{ Metilxantinas Totais $\left(\mathrm{mg} \mathrm{g}^{-1}\right)$} \\
\hline SF & $0,87 \mathrm{a}$ & $1,08 \mathrm{a}$ & $0,92 \mathrm{a}$ & $1,05 \mathrm{a}$ & $1,10 \mathrm{ab}$ & $1,14 \mathrm{a}$ \\
$\mathrm{FC}$ & $0,92 \mathrm{a}$ & $1,12 \mathrm{a}$ & $0,92 \mathrm{a}$ & $1,09 \mathrm{a}$ & $1,21 \mathrm{a}$ & $1,16 \mathrm{a}$ \\
FLL & $0,96 \mathrm{a}$ & $0,92 \mathrm{~b}$ & $0,96 \mathrm{a}$ & $1,19 \mathrm{a}$ & $1,08 \mathrm{~b}$ & $1,26 \mathrm{a}$ \\
$\mathrm{CV}(\%)$ & 8,32 & 6,083 & 6,53 & 9,13 & 4,35 & 5,37 \\
\hline \multicolumn{7}{c}{ Compostos Fenólicos Totais $\left(\mathrm{mg} \mathrm{g}^{-1}\right)$} \\
\hline SF & $120,50 \mathrm{a}$ & $115,67 \mathrm{a}$ & $118,42 \mathrm{a}$ & $128,09 \mathrm{a}$ & $130,00 \mathrm{a}$ & $126,84 \mathrm{a}$ \\
FC & $119,28 \mathrm{a}$ & $128,04 \mathrm{a}$ & $117,33 \mathrm{a}$ & $129,92 \mathrm{a}$ & $129,04 \mathrm{a}$ & $129,35 \mathrm{a}$ \\
FLL & $117,02 \mathrm{a}$ & $125,94 \mathrm{a}$ & $117,93 \mathrm{a}$ & $128,90 \mathrm{a}$ & $126,50 \mathrm{a}$ & $130,11 \mathrm{a}$ \\
$\mathrm{CV}(\%)$ & 6,26 & 4,25 & 4,61 & 3,88 & 2,96 & 3,38 \\
\hline Em que: Valores médios na mesma coluna seguidas da mesma letra não diferem entre si pelo teste de Tukey a 5\%
\end{tabular}
de probabilidade. $\mathrm{SF}=$ sem fertilização; $\mathrm{FC}=$ fertilização convencional; $\mathrm{FLL}=$ fertilização de liberação lenta; $\mathrm{CV}=$ coeficiente de variação.

a luminosidade de $30 \%$. Os dados apresentados para a luminosidade $30 \%$ e $60 \%$ estão de acordo com a teoria do balanço entre carbono/nutriente proposta por Bryant, Chapin III e Klein (1983), na qual condições ambientais capazes de limitar a fotossíntese diminuem a produção de substâncias não nitrogenadas, enquanto a produção de substâncias nitrogenadas é favorecida. Ainda, segundo Bryant, Chapin III e Klein (1983), o interior das florestas, cujo sombreamento das árvores dos estratos superiores diminui a intensidade de luz disponível para as plantas nos estratos intermediários e inferiores, é uma das situações em que se verificam estas condições ambientais desfavoráveis com relação à luminosidade.

Medrado e Mosele (2004) destacam a importância de linhas de pesquisas no campo da investigação sobre sombreamento e consórcio com outras espécies florestais dos ervais, bem como a caracterização dos compostos fitoquímicos produzidos por essas associações no manejo florestal. Schubert et al. (2006), ao estudarem a variação de teores de MXT em erva-mate de distintas procedências, encontraram teores de 1,77 a $10,37 \mathrm{mg} \mathrm{g}^{-1}$, sendo que os menores teores foram detectados nas amostras coletadas entre os meses de menor atividade de biossíntese da planta (junho a agosto). Segundo Silva (2012), há uma tendência de diminuição na produção de cafeína e metilxantinas totais ao longo do tempo, uma vez que os teores são menores em folhas de seis meses, intermediários em folhas de dois meses e maiores em folhas de brotação. Contudo, muitos outros fatores podem influenciar nos teores de metilxantinas, como idade da planta, luminosidade, período de colheita, época da poda e genética. Essas variáveis vêm sendo estudadas com a finalidade de padronizar os teores de metilxantinas (COELHO; MARIATH; SCHENKEL, 2002; DA CROCE, 2002; SCHUBERT et al., 2006).

Os altos teores de metilxantinas identificados no verão obtidos por Schubert et al. (2006) podem ser atribuídos às folhas jovens, em desenvolvimento, pois os resultados do final de outono e inverno podem indicar folhas mais velhas, maduras, e com baixa atividade biossintética. Os dados apresentados no trabalho corroboram esta teoria e podem ser usados para avaliar e melhorar os sistemas consorciados com esta espécie, em especial para aprimorar as técnicas silviculturas de fertilização e manejo de luminosidade do povoamento.

Compostos Fenólicos Totais

Ci. Fl., v. 27, n. 4,out.-dez., 2017 
Com relação aos teores de CFT, verificou-se, através da comparação dos resultados da primeira estação de crescimento de 2011 e da segunda, em 2012, que não houve influência dos tratamentos de luminosidade e fertilizações, não havendo diferença estatística na análise comparativa dentro dos três níveis de luminosidade aparente e fertilização (Tabela 2). Observou-se nos dados obtidos que houve um acréscimo quantitativo nos teores de CFT e que ocorreram nas folhas produzidas no sítio de $45 \%$ e $30 \%$ de luminosidade aparente, de forma similar ao descrito por Rachwal et al. (2002). Teores menores de CFT, em ervais consorciados com outras espécies florestais e de menor luminosidade, foram encontrados por Strassmann et al. (2008), quando comparados com o cultivo de erva-mate a pleno sol. Em ambientes com excesso de luz, a produção de CFT é maior, pois eles protegem a planta, absorvendo o excesso de raios ultravioleta. $\mathrm{O}$ aumento na intensidade luminosa eleva os teores de CFT em diversas plantas (DUDT; SHURE, 1994). Também é citado na literatura que os compostos fenólicos como os flavonoides funcionam como antibióticos, pesticidas naturais, atraentes para polinizadores, agentes protetores contra a luz ultravioleta, impermeabilizantes da parede celular ao gás e à água e como material estruturante, para dar estabilidade a planta (NACZK; SHAHIDI, 2004).

Leis et al. (2009) identificaram o ácido clorogênico como fator de resistência de tripes em crisântemo, e Kim e Sano (2008) sugeriram que a cafeína estimula os sistemas de defesa endógenos das plantas, através da ativação direta ou indireta da expressão gênica. No entanto, vantagens com sombreamento moderado podem ser observadas sobre os teores de outros constituintes químicos: o aumento do conteúdo de potássio causa uma redução dos CFT (RACHWAL et al., 2000). Compostos fenólicos como o ácido clorogênico, que é observado em erva-mate (FILIP et al., 2001), podem contribuir para o amargor e adstringência, características consideradas negativas entre os consumidores. Houve uma tendência quantitativa de incremento na estação de crescimento de 2012, se comparado com o ano anterior, podendo ser uma resposta da planta à fertilização. O incremento de teores de CFT, quando comparados com o ano anterior, foi verificado em dois tratamentos que receberam adubação na luminosidade de 30 e $60 \%$. Em ambos os níveis

TABELA 2: Comparação entre duas estações de crescimento dos teores foliares de metilxantinas totais e compostos fenólicos totais em erva-mate, cultivadas sob diferentes níveis de luminosidade e fertilizantes.

TABLE 2: Comparison between two growing seasons of foliar content of total methylxanthines and phenolic compounds in mate tea, under different luminosity and fertilizers.

\begin{tabular}{|c|c|c|c|c|c|c|c|c|c|c|c|c|}
\hline & \multicolumn{4}{|c|}{$60 \%$} & \multicolumn{4}{|c|}{$45 \%$} & \multicolumn{4}{|c|}{$30 \%$} \\
\hline & 2011 & 2012 & Teste $\mathrm{F}^{1}$ & $\mathrm{CV}(\%)$ & 2011 & 2012 & Teste $\mathrm{F}^{1}$ & $\mathrm{CV}(\%)$ & 2011 & 2012 & Teste $\mathrm{F}^{1}$ & $\mathrm{CV}(\%)$ \\
\hline \multicolumn{13}{|c|}{ Metilxantinas Totais $\left(\mathrm{mg} \mathrm{g}^{-1}\right)$} \\
\hline SF & $0,874 \mathrm{a}$ & $1,056 \mathrm{a}$ & $\mathrm{F}_{(1 ; 4)} 3,6^{\mathrm{ns}}$ & 12,1 & 1,087 a & 1,107 a & $\mathrm{F}_{(1 ; 4)} 0,2^{\mathrm{ns}}$ & 4,2 & $0,925 \mathrm{~b}$ & 1,149 a & $F_{(1 ; 4)} 9,8^{*}$ & 8,4 \\
\hline $\mathrm{FC}$ & $0,925 \mathrm{a}$ & $1,095 \mathrm{a}$ & $\mathrm{F}_{(1 ; 4)} 6,3^{\mathrm{ns}}$ & 8,2 & $1,125 \mathrm{a}$ & $1,212 \mathrm{a}$ & $\mathrm{F}_{(1 ; 4)} 4,1^{\mathrm{ns}}$ & 4,4 & $0,928 \mathrm{~b}$ & $1,165 \mathrm{a}$ & $\mathrm{F}_{(1 ; 4)} 103,7 * *$ & 2,7 \\
\hline FLL & $0,966 \mathrm{~b}$ & $1,193 \mathrm{a}$ & $\mathrm{F}_{(1 ; 4)} 20,0^{*}$ & 5,7 & $0,921 \mathrm{~b}$ & $1,081 \mathrm{a}$ & $\mathrm{F}_{(1 ; 4)} 7,9^{*}$ & 6,9 & $0,961 \mathrm{~b}$ & $1,262 \mathrm{a}$ & $\mathrm{F}_{(1 ; 4)} 40,8 * *$ & 5,2 \\
\hline \multicolumn{13}{|c|}{ Compostos Fenólicos Totais $\left(\mathrm{mg} \mathrm{g}^{-1}\right)$} \\
\hline SF & $120,5 \mathrm{a}$ & $128,0 \mathrm{a}$ & $\mathrm{F}_{(1 ; 4)} 0,8^{\mathrm{ns}}$ & 8,0 & 115,6 a & $130,0 \mathrm{a}$ & $F_{(1 ; 4)} 7,6^{\mathrm{ns}}$ & 5,1 & $118,4 \mathrm{a}$ & $126,8 \mathrm{a}$ & $\mathrm{F}_{(1 ; 4)} 2,4^{\mathrm{ns}}$ & 5,4 \\
\hline $\mathrm{FC}$ & $119,2 \mathrm{~b}$ & 129,9 a & $F_{(1 ; 4)} 9,6^{*}$ & 3,3 & $128,0 \mathrm{a}$ & $129,0 \mathrm{a}$ & $\mathrm{F}_{(1 ; 4)} 0,7^{\mathrm{ns}}$ & 1,1 & $117,3 \mathrm{~b}$ & 129,3 a & $\mathrm{F}_{(1 ; 4)} 27,1 * *$ & 2,2 \\
\hline FLL & $117,0 \mathrm{~b}$ & 128,9 a & $\mathrm{F}_{(1 ; 4)} 48,0 * *$ & 1,7 & 125,9 a & $126,5 \mathrm{a}$ & $\mathrm{F}_{(1 ; 4)} 0,0^{\mathrm{ns}}$ & 3,5 & $117,9 \mathrm{~b}$ & $130,1 \mathrm{a}$ & $\mathrm{F}_{(1 ; 4)} 10,5^{*}$ & 3,7 \\
\hline
\end{tabular}

Em que: médias na mesma linha seguidas da mesma letra não diferem entre si pelo teste de Tukey a $5 \%$ de probabilidade. O Teste de $\mathrm{F}$ foi realizado para comparar os dois anos de produção. ${ }^{1}$ Teste $\mathrm{F}$ : * significativo a $5 \%$; ** significativo a $1 \%$; ns = não significativo. $\mathrm{SF}$ = sem fertilização; FC = fertilização convencional; FLL = fertilização de liberação lenta; $\mathrm{CV}=$ coeficiente de variação. 
de luminosidade, os teores foram maiores de um ano para outro, nos tratamentos com FC e FLL (Tabela 2).

Os teores obtidos para CFT mostraram-se similares aos levantados por Borille, Reissmann e Freitas (2005), embora superiores aos de Valduga (1995), Rachwal et al. (2000) e Zampier (2001). Tais diferenças podem estar ligadas à idade das folhas, procedência, insolação e mecanismo de defesa contra herbivoria, entre outros (MISRA; MISRA; DWIVEDI, 1999). Verificou-se que os tratamentos 30\% FC e 30\% FLL apresentaram teores maiores no ano de 2012, comparativamente com o ano de 2011, de 10,2 e $10,3 \%$, respectivamente. Para a luminosidade de $45 \%$, não houve diferenciação entre os tratamentos na comparação entre as duas estações de crescimento (Tabela 2).

Assim, como os resultados encontrados por Mazzafera (1994), os dados obtidos no presente trabalho sugerem que a presença de CFT em tecidos foliares de I. paraguariensis é de alguma forma, regulada positivamente pela intensidade da radiação solar à qual as culturas estão expostas, em particular em sistemas consorciados. No entanto, possíveis influências relevantes de outros fatores abióticos e bióticos não devem ser negligenciadas.

\section{CONCLUSÕES}

A fertilização da erva-mate associada aos níveis de luminosidade aparente não promoveram o aumento de teores de metilxantinas totais e compostos fenólicos totais.

A luminosidade aparente de $30 \%$ estabeleceu o melhor indicador para obtenção de metilxantinas, sendo que a fertilização FC apresentou a maior produção de metilxantinas quando submetida à luminosidade aparente de $30 \%$ e $45 \%$.

Houve incremento do teor dos compostos fenólicos da estação de crescimento 2011 para 2012, promovido pelos tratamentos fertilizados com FLL e FC sob a luminosidade aparente de $30 \%$ e $60 \%$.

\section{REFERÊNCIAS}

ANGELO, P. M.; JORGE, J. Compostos fenólicos em alimentos - uma breve revisão. Revista do Instituto Adolfo Lutz, São Paulo. v. 66, n. 1, p. 232-240, 2007.

ASHIHARA, H.; SUZUKI, T. Distribution and biosynthesis of caffeine in plants. Front Bioscience, Califórnia, v. 9, n. 2, p. 1864-76, 2004.

BORILLE, A. M. W.; REISSMANN, C. B.; FREITAS, R. J. S. Relação entre compostos fitoquímicos e o nitrogênio em morfotipos de erva-mate (Ilex paraguariensis St. Hil.). Boletim do Centro de Pesquisa de Processamento de Alimentos, Curitiba, v. 23, p. 183-196, 2005.

BORTOLUZZI, A. L. M. et al. Quantificação de metilxantinas e compostos fenólicos em amostras comerciais de erva-mate (Ilex paraguariensis St. Hil.). In: CONGRESO SUDAMERICANO DE LA YERBA MATE, 4., 2006, Posadas. Anais ... Posadas: INYM; INTA; UNAM; EPAGRI, 2006. p. 143-147.

BRAVO, L.; GOYA, L.; LECUMBERRI, E. LC/MS characterization of phenolic constituents of mate (Ilex paraguariensis, St. Hil.) and its antioxidant activity compared to commonly consumed beverages. Food Research International, Toronto, v. 40, p. 393-405, 2007.

BRYANT, J. P.; CHAPIN III, F. S.; KLEIN, D. R. Carbon/nutrient balance of boreal plants in relation to vertebrate herbivory (hare Lepuscapensis). Oikos, Copenhagem, v. 40, n. 3, p. 357-368, 1983.

BUGARDT, A. C. Desenvolvimento de uma bebida utilizando extrato de erva-mate verde (Ilex paraguariensis St. Hil). 2000. 124 f. Dissertação (Mestrado em Tecnologia Química) - Universidade Federal do Paraná, Curitiba, 2000.

CARDOSO JÚNIOR, E. L. Teores de metilxantinas e compostos fenólicos em extratos de erva-mate (Ilex paraguariensis St. Hil.). 2006. 142 f. Tese (Doutorado em Agronomia) - Universidade Estadual de Maringá, Maringá, 2006.

COELHO, G. C. et al. Efeito do sombreamento sobre a sobrevivência, morfologia e química da erva-mate. In: CONGRESSO SUL-AMERICANO DA ERVA-MATE, 2.; Reunião TÉCNICA DO CONE SUL SOBRE A CULTURA DA ERVA-MATE, 3., 2000, Encantado. Anais... Porto Alegre: UFRGS; 
FEPAGRO, 2000. p. 396-399.

COELHO, G. C.; MARIATH, J. E. A.; SCHENKEL, E. P. Populational diversity on leaf morphology of maté (Ilex paraguariensisA. St.-Hil. Aquifoliaceae). Brazilian Archives of Biology and Technology, Curitiba, v. 45, p. 47-51. 2002.

DA CROCE, D. M. Características físico-químicas de extratos de erva-mate (Ilex paraguariensis St. Hil) no estado de Santa Catarina. Ciência Florestal, Santa Maria, v. 12, n. 2, p. 107-113, 2002.

DEGÁSPARI, C. H.; WASZCZYNSKYJ, N. Propriedades antioxidantes de compostos fenólicos. Visão Acadêmica, Curitiba, v. 5, n. 1, p. 33-40, 2004.

DUDT, J. F.; SHURE, D. J. The influence of ligth and nutrients on foliar phenolics and insect herbivory. Ecology, Brooklyn, v. 75, n. 1, p. 86-98, 1994.

DUTRA, F. L. G.; HOFFMANN-RIBANI, R.; RIBANI, M. Determinação de compostos fenólicos por cromatografia líquida de alta eficiência isocrática durante estacionamento da erva-mate. Química Nova, São Paulo, v. 33, n. 1, p. 119-123, 2010.

EMBRAPA. Sistema brasileiro de classificação de solos. 2. ed. Rio de Janeiro: Centro Nacional de Pesquisa de Solos, 2006.

FILIP, R. et al. Phenoliccompounds in seven South American Ilex species. Fitoterapia, Kidlington, v. 72, p. 774-778, 2001.

GOBBO-NETO, L.; LOPES, N. P. Plantas medicinais: fatores de influência no conteúdo de metabólitos secundários. Química Nova, São Paulo, v. 30, n. 2, 2007.

GUGLIUCCI, A. Antioxidant effects of Ilex paraguariensis: induction of decreased oxidability of human LDL in vivo. Biochemical and Biophysical Research Communications, New York, v. 224, p. 338-344, 1996.

INSTITUTO AGRONÔMICO DO ESTADO DO PARANÁ. Cartas climáticas do Estado do Paraná 1994. Londrina: IAPAR, 1994. 49 p. (Documento, 18).

KIM, Y. Y.-S.; SANO, H. Pathogen resistance of transgenic tobacco plants producing caffeine. Phytochemistry, New York, v. 69, n. 4, p. 882-888, 2008.

MACCARI JUNIOR, A.; MAZUCHOWSKI, J. Z. Produtos alternativos e desenvolvimento da tecnologia industrial na cadeia produtiva da erva-mate. Curitiba: Câmara Setorial da Cadeia Produtiva da Erva-Mate; MCT; CNPq; Projeto PADCT Erva-Mate, 2000. 176 p.

MAZUCHOWSKI, J. Z. Influência de níveis de sombreamento e de nitrogênio na produção de massa foliar da erva-mate (Ilex paraguariensis St. Hill). 2004. 112 f. Dissertação (Mestrado em Ciência do Solo) - Universidade Federal do Paraná, Curitiba, 2004.

MAZUCHOWSKI, J. Z. Patentes industriais e as prioridades para os investimentos tecnológicos na cadeia produtiva da erva-mate. Curitiba: EMATER, 2000. 178 p. (Serie PADCT da Erva-Mate, n. 2).

MAZUCHOWSKI, J. Z.; RUCKER, N. G. A. Diagnóstico e alternativas para a erva-mate Ilex paraguariensis St. Hil. Curitiba: Secretaria de Estado da Agricultura e do Abastecimento, 1993. 141 p. MAZZAFERA, P. Caffeine, theobromine and theophylline distribution in Ilex paraguariensis. Revista Brasileira de Fisiologia Vegetal, Campinas, v. 62, n. 2, p. 149-151,1994.

MEDRADO, M. J. S.; MOSELE, S. H. O futuro da investigação científica em erva-mate. Colombo: Embrapa Florestas, 2004.

MELLO, E. A.; GUERRA, N. B. Ação antioxidante de compostos fenólicos naturalmente presentes em alimentos. Ciência e Tecnologia de Alimentos, Campinas, v. 36, n. 1, p. 1-11, 2002.

MERCOMATE. Economia Ervateira no MERCOSUL. Brasília: Agência Brasileira de Cooperação do Ministério das Relações Exteriores, 1993. 10 p.

MISRA, S. P.; MISRA, V.; DWIVEDI, M. Recent advances in biosynthesis of alkaloid. In: BARTON, S. D.; NAKANISHI, K.; METH-COHN, O. Comprehensive natural products chemistry. London: Elsevier, 1999. v. 4.

NACZK, M.; SHAHIDI, F. Extraction and analysis of phenolics in food (Review). Journal of Chromatography A. Amsterdam, v. 1054, n. 1-2, p. 95-111, 2004.

NIETSCHE, K. Caracterização da qualidade da erva-mate cancheada. 2002. 89 f. Dissertação (Mestrado em Tecnologia Química) - Universidade Federal do Paraná, Curitiba, 2002.

OLIVEIRA, A. C. et al. Procedimentos de coleta para análise foliar de essências florestais 
(araucária, erva-mate, palmito, eucalipto, pinus). Curitiba: Universidade Federal do Paraná, Projeto de Extensão Universitária Solo Planta, 2001. (Folder).

OLIVEIRA, T. T. et al. Ação antioxidante dos flavonóides. In: COSTA, N. M. B.; ROSA, C. O. B. (Ed.). Alimentos Funcionais. Viçosa, MG: Editora Folha de Viçosa, 2006. p. 31-56.

OLIVEIRA, Y. M. M.; ROTTA, E. Área de distribuição natural da erva-mate. In: SEMINÁRIO SOBRE ATUALIDADES E PERSPECTIVAS FLORESTAIS: SILVICULTURA DA ERVA-MATE. 10., 1983, Curitiba. Anais.... Curitiba: EMBRAPA, CENTRO NACIONAL DE PESQUISA DE FLORESTAS, 1985. p. 17-36. (Documentos, 15).

RACHWAL, M. F. G. et al. Influência da luminosidade sobre a produção de massa foliar e teores de macronutrientes, fenóis totais, cafeína e teobromina em folhas de erva-mate. Colombo: EMBRAPA CNP Florestas, 2002. 5 p.

RACHWAL, M. F. G. et al. Influência da luminosidade sobre a produtividade da erva-mate(Ilex paraguariensis St. Hil.) aos quatro anos e quatro meses de idade sobre Latossolo Vermelho-amarelo Distrófico em São Mateus do Sul, PR. In: CONGRESSO SUL-AMERICANO DA ERVA-MATE, 1.; REUNIÃO TÉCNICA DO CONE SUL SOBRE A CULTURA DA ERVA-MATE, 2., 1998, Curitiba. Anais... Curitiba, 1998. p. 445.

RACHWAL, M. F. G. et al. Influência da luminosidade sobre os teores de macronutrientes e tanino em folhas de Erva-mate(Ilex paraguariensis St. Hil.) In: CONGRESSO SULAMERICANO DA ERVA-MATE, 2.; REUNIÃO TÉCNICA DO CONE SUL SOBRE A CULTURA DA ERVA-MATE, 3., 2000, Encantado. Resumos... Encantado, 2000. p. 225.

RODERJAN, C. V. et al. As unidades fitogeográficas do estado do Paraná. Ciência e Ambiente, Santa Maria, n. 24, p. 75-92, 2002.

SCHERER, R. et al. Inheritance studies of caffeine and theobromine content of Mate (Ilex paraguariensis) in Misiones, Argentina. Euphytica, Wageningen, v. 126, p. 203-210, 2002.

SCHINELLA, G. R. et al. Antioxidant effects of an aqueous extract of Ilex paraguariensis. Biochemical and Biophysical Research Communications, New York, v. 269, p. 357-360, 2000.

SCHUBERT, A. et al. Variação anual de metilxantinas totais em amostras de Ilex paraguariensis A. St. - Hil. (erva-mate) em Ijuí e Santa Maria, Estado do Rio Grande do Sul. Química Nova, São Paulo, v. 29, n. 6, p. 1233-1236, 2006.

SILVA, C. H. B. Influência da idade das folhas e da luminosidade nos teores de metilxantinas, ácido clorogênico, fenólicos totais e na atividade de captação de radicais livres de extratos aquosos de Ilex paraguariensis A. St. Hilaire. 2012. Dissertação (Mestrado em Farmácia) - Universidade Federal de Santa Catarina, Florianópolis, 2012.

STEEL, R. G. D.; TORRIE, J. H. Principles and procedures of statistics with special reference to the biological sciences. New York: McGraw Hill, 1960. $481 \mathrm{p}$.

STRASSMANN, B. B. et al. Quantitation of methylxanthinic alkaloids and phenolic compounds in mate (Ilex paraguariensis) and their effects on blood vessel formation in chick embryos. Journal of agricultural and food chemistry, Washington, v. 56, n. 18, 2008.

TAIZ, L.; ZEIGER, E. Fisiologia Vegetal. 3. ed. Porto Alegre: Artmed, 2004. 719 p.

VALDUGA, E. Caracterização química e anatômica da Folha de Ilex paraguariensis St. Hil. e de algumas espécies utilizadas na adulteração do mate. 1995. Dissertação (Mestrado em Tecnologia Química) - Universidade Federal do Paraná, Curitiba, 1995.

ZAMPIER, A. C. Avaliação dos níveis dos nutrientes, cafeína e taninos em erva-mate (Ilex paraguarienis St. Hil.) após adubação e sua relação com a produtividade. 2001. 94 f. Dissertação (Mestrado em Engenharia Florestal) - Universidade Federal do Paraná, Curitiba, 2001. 